of the S. temperate belt, and the intervening zone between it and the N. tropical belt was occupied by a remarkable series of bright elliptical formations, usually accompanied by dark condensations on the south preceding side. These elliptical forms appear on all the photographs taken during 1916 , and are probably to be interpreted as representing cyclones.

\section{THE INSTITUTION OF NAVAL ARCHITECTS}

THE spring meetings of the Institution of Naval Architects were lield in the rooms of the Royal Society of Arts on March 28 and 29. In the unavoid. able absence of the president-the Earl of Durhamthe Marquis of Bristol took the chair and delivered an address, in which he referred to the question of the formation of a council for co-ordinating the common interests of the various institutions representing engineering professions. Such a council, in making recommendations, would have the weight of the whole profession behind it.

The Elgin scholarship has keen awarded to Mr. R. J. Shepherd, and the annual gold medal to Prof. T. B. tbell for his paper on experiments to determine the resistance of bilge keels to rolling. A premium has been awarded to Mr. A. T. Wall for his paper on some effects of the Bulkhead Committee's report in practice.

Despite the disadvantages under which the institution has been placed owing to so many of its members being engaged on work intimately connected with the war, thirteen papers were read and discussed. The standard of the papers has in no way diminished, and many contain matter of considerable scientific interest.

Mr. D. B. Morison's paper on standardisation as applied to the machincry for cargo-boats is of much interest at the present time, when a strong effort is being made to make good losses due to piratical submarine operations. A specification for such machinery is being discussed now by the North-East Coast Institution, and an appzal was made for joint action by all the institutions connected with shipbuilding. An interesting feature of Mr. Morison's paper is the many references to economic problems. It is futile for capital to expect that labour will consent to any great reduction in wages, and equarly hopeless for labour to expect the maintenance of the present high rate of wages without concession on its part. To render it possible to pay high wages in the future and yet maintain our trade, the requisites are (i) a candid acknowledgment by labour of the economic law that good general trade is dependent on maximum production, and (ii) capital must recognise that maximum production entails correspondingly high pay.

Mr. J. Montgomerie contributed a valuable paper giving an account of experiments conducted at the West Ham Technical Institute on stress determination in a flat plate. In these experiments the plates were bolted in a very heavy frame, rectangular in plan, leaving a surface of plate measuring $4 \mathrm{ft}$. by $2 \mathrm{ft}$. exposed to water-pressure. The object was to hold the plate round the edges as rigidly as possible. Bach's plateswhich constitute the only experimental work on the large scale up to the present-were not held so rigidly at the edges Crawford's experiments on the same subject were on too small a scale. Mr. Montgomerie has experimented on several plates of various thicknesses; the plate $0 \cdot 75$ in. thick alone is reported upon in the paper, although the experiments on the other plates have been completed.

Measurements of defiection were made at many stations on the plate, and curves plotted showing the cross-sections in directions pardlel to the edges. From these curves, by application of graphical methods, the stresses at the station.s were determined. Owing to the nature of the graphical methods employed, it was considered desirable that the strains in the plate should be measured directly, and for this purpose a strainmeter was devised by Mr. J. Duncan and used in such a manner as to determine the principal axes of strain at the stations. The principal strains were then measured at each station, and from the knowledge thus obtained, together with the measured values of Young's modulus and Poisson's ratio for the material, the principal stresses were determined and the ellipses of stress drawn for each station. The results by these two methods show very fair agreement.

The resulting diagram is very interesting, and shows the elastic behaviour of the entire plate. It shows that the maximum stress actually occurs at the centre of the plate and not at the frame ends of the short diameter, as has been supposed hitherto. There is no doubt that this fact is due to the elastic movements of the portion of the plate clamped in the frame, which permit the "wall secti.n " to assume slope instead of remaining in the plane of the wall, as is assumed in the usual mathemati al theory The effect of this behaviour is to diminish the bending moment at the plate edges and to increase that at the centre; the stresses, of course, alter correspondingly. Mr. Montgomerie has promised further information regarding the other thinner plates tested, and his contribution must be regarded as a valuable addition to our knowledge of cases of complex stresses.

Mr. Thomas Graham described an apparatus for interpreting stability for the use of shipmasters, whereby the stability of vessels under any ordinary conditions of loading can be shown graphically and easily interpreted. This instrument illustrates three features of stability which are of most practical importance, viz. :-(i) An automatic record of the variation of the righting arm as the ship heels over from the upright to the vanishing angle. (ii) The approximate angle of heel at which the freeboard deck edge becomes awash. (iii) The position of the water-line throughout the range of moderate angles met with in practice. The appliance consists of a pivoted wooden lamina representing a cross-section of the ship, and having a pointer moving over a protractor showing angles of heel. A plumb line is hung from the position on the lamina corresponding to the known centre of gravity of the ship. A brass plate having a curved edge representing the metacentric evolute for the given draught and displacerent is attached to the lamina, and another plumb line is arranged to pass over the edge of this evolute and to hang tangentially. The distance between the wo plumb lines thus shows to scale the magnitude of the actual righting lever at all angles of heel. An additiona. feature is an arrangement for indicating the position of the water-line.

Prof. W. E. Dalby read a paper illustrating the inner structure of mild steel, and showing how its strength is correlated with this inner structure. This paper is one of the most readable produced up to date, and contains explanations which can be followed readily by reference to the many micrographs in. cluded. Load extension diagrams of all the steels have been obtained by use of the author's well-known apparatus.

Lieut. Walter A. Sonble contributed a paper on the design of pin joints based on ultimate strength. The author gives reasons leading to the conclusion that the maximum load carried is the best criterion for the strength of a pin joint, and describes in detail a method by which the calculations required in designing a joint can be made.

Mr. J. J. King-Salter gave an account of some experiments on the influence of running balance of propellers on the vibration of ships. Since the introduction of turbines in warships, running at a much higher NO. 2475, VOL. 99] 
speed than reciprocating engines, the necessity of seeing that the propeliers were suitable not only as regards form, but also as regards their being in proper mechanical balance, has received considerably more attention. Experiments have been carried out in two destroyers and a Town class cruiser built at the Commonwealth Naval Lockyard at Sydney. The paper describes experiments made by rotating the propeller at speed on spring bearings, noting the vibration and removing material from ${ }_{1}$ certain parts of the blade and even the boss. From subsequent observations on the ships it was apparent that there was a decided improvement. The problem to be solved is by no means easy, since removal of material from the blades of a propeller has the effect of altering the pitch, and naval architects, as a rule, have very stringent specifications regarding the exactitude of the pitch of a propeller.

Sir George Greenhill contributed d paper on the theory of wave-motion on water. In this paper the author discusses mathematically the trochoidal wave as treated by Rankine. Mr. John H. Macalpine gave particulars of marine applications of reduction gears of the floating-frame type. The success of this type of gear appears to be very marked. The first floatingframe gear was installed at Granite City, Illinois, in I9II; when examined on April 30, I9I6, the scraper marks were still visible on the gear teeth. Originally these marks were of imperceptible depth.

Messrs. P. A. Hillhouse and W. H. Riddlesworth presented a paper on la: nching. This paper contains an account of some interesting experiments made at the Fairfield Shipbuilding Yard. A model of the ship was constructed and arranged in all respects to be a reduced copy. Model ways were constructed and a tank arranged with water at proper tide level. By these means valuable information was obtained regarding the motion of the ship during launching. The authors make an interesting suggestion whereby an accurate record of the complete motion of the actual vessel from start to finish might be obtained by means of the kinematograph. Two machines would be required, one placed near the stern of the vessel when on the slip, and the other somewhat less than the length of the vessel further aft. Both would stand at a convenient distance away from the vessel's side, and would have their axes at right angles to the middle line of the berth. In the field of view of each, two uprights would be placed as near to the vessel's side as possible, and on each upright a vertical scale of feet would be clearly marked in black and white. On the ship's side would be painted a continuous longitudinal white line crossed by short vertical lines numbered in succession from either end As the vessel moved the cameras would record continuously the movements of the white line in relation to the ship and to the water level and ground ways, and the whole motion could be reconstructed. If, in addition, there could be praced in front of each camera a large clock-face with seconds pointer, the two sets of photographs could be correlated and a record of velocities obtained.

\section{BRITISH FILTER-PAPERS.}

$A \mathrm{~S}$ is well known to laboratory workers, in preA war days the better kinds of filter-paper used in chemical operations were not produced in this country. They were imported chiefly from Germany and Sweden. In particular, the so-called "ashless" filters, from whi, h most of the mineral matters have been extracted by treatment with hydrochloric and hydrofunric acids, had made the name of one German firm familiar in probably every chemical laboratory of importance throughout the kingdom. The outNO. 2475, VOL. 99 ? break of war, however, stopped the supply of German filters, and British paper-makers turned their attention to meeting the demand.

The qualities required in filter-paper depend upon the purpose to which it is to be applied. Thus for certain technical operations, such as the filtration of oils and fruit juices, a soft paper of open texture is desirable. Further, as such paper is often used for filtration under pressure, a high degree of elasticity is required in it to prevent fracture. In analytical work, on the other hand, whilst a paper with open texture which filters rapidly is preferable for flocculent precipitates like ferric hydroxide, a close-texture paper is required for the retention of fine precipitates such as barium sulphate. Moreover, the proportion of mineral matter is important. Compounds of calcium and iron, frequently with a little copper, and sometimes silica and alumina, are the chief mineral impurities found in filter-paper; and for accurate quantitative work the amount of these should be small. Indeed, it should preferably be so small as to be negligible except where a high degree of exactitude is required. In any case, it should be definitely known, and ought always to be stated on the packets of filters by the makers.

The ability to retain fine precipitates, a minimum proportion of ash, and reasonable rapidity of filtra. tion are thus the chief desiderata in the best filters for chemical laboratory purposes. The last alone is sufficient in many technical operations. Discussing this question in the Analyst some months ago, Messrs. Bevan and Bacon indicated that for paper required to filter with moderate rapidity the ratio of the volume of the paper to that of its constituent fibres should be about 3.5 to $\mathrm{I}$. It does, in fact, as a rule vary between the limits 3 and 4.5 to 1 . "Pinholes " are sometimes found in paper having this ratio or "bulk" (as the technical term goes); they are attributable to faults in the milling.

Some time ago specimens of the filter-papers now produced in this country were supplied to us by three manufacturing firms, namely, Messrs. W. and R. Balston, Ltd., Maidstone; Messrs. I. Barcham Green and Son, Maidstone; and Messrs. Evans, Adlard and Co., Ltd. Winchcombe. Judging by the reports furnished with certain of the papers, supplemented by tests applied in actual working practice, a number of the samples compare quite well with the foreign filters which they have replaced. It is evident that a serious endeavour is being made to produce filters which will compare favourably in quality with even the best of those hitherto imported, and the efforts appear to have met already with a considerable measure of success. Naturally, it will take time and careful study completely to outvie the foreign articles, which are the result of long specialisation. Uniformity of product is an important point to aim at, so that the user may know that he can rely upon the constancy of the quality. There is no obvious reason why British paper-makers should not, with proper technical advice, compete successfully with foreign manufacturers in this branch of industry, and, in fact, there is good reason to believe that they will do so. In this matter, as in so many others, we ought not to have to revert to the status quo ante bellum.

\section{COMPULSORY CONTINLATION CLASSES.}

$T H E$ final report of the Departmental Cormmtee on Juvenile Education in Relation to Employment after the War has just been issued (Cd. $S_{5}$ i2, price $6 d$, net).

The terms of reference of the committee were: To consider what steps should be taken to make 